\title{
Resitividade Elétrica Aplicada à Mineralizações Manganesíferas em Castanheira, MT
}

Moara Maria Oliveira de Matos, UnB; Welitom Rodrigues Borges, UnB; Vicente de Paula Pinto, UnB; Ciro Calachibete, UnB; Maria Clara Lopes Paula, UnB; Isabela Resende Almeida, UnB.

Copyright 2019, SBGf - Sociedade Brasileira de Geofísica

This paper was prepared for presentation during the $16^{\text {th }}$ International Congress of the Brazilian Geophysical Society held in Rio de Janeiro, Brazil, 19-22 August 2019.

Contents of this paper were reviewed by the Technical Committee of the $16^{\text {th }}$ International Congress of the Brazilian Geophysical Society and do not necessarily represent any position of the SBGf, its officers or members. Electronic reproduction or storage of any part of this paper for commercial purposes without the written consent of the Brazilian Geophysical Society is prohibited.

\section{Abstract}

This paper presents the electrical resistivity model obtained from apparent resistivity values, acquired in Castanheira, Mato Grosso state, to identify manganese mineralizations. In the area were performed 5 resistivity electric profiles with investigated until 36 depth meters. Results shown that manganese ore appears on the sections as a low resistivity anomaly (values under 200 $\Omega . m)$. In contrast, Serra da Providência granite presents resistivity values above $2000 \Omega$.m. Intermediary values are interpreted as weathered granites.

\section{Introdução}

A geofísica, como parte fundamental no trabalho de prospecção mineral, contribui com a redução dos riscos do processo de exploração e direciona a descoberta de depósitos minerais. Esta, envolve o estudo das propriedades físicas das rochas e seus constituintes para a caracterização do ambiente geológico. O contraste entre um material e o meio adjacente é o requisito para que a metodologia geofísica seja aplicada. A geofísica de prospecção investiga os primeiros cinco quilômetros da crosta terrestre (Luiz, 2013) através das variações das propriedades físicas relacionadas à concentração de minerais ou às estruturas que os abrangem.

$\mathrm{Na}$ região de Castanheiras, estado de Mato Grosso, ocorrem depósitos manganesíferos primários e secundários associados a rochas ígneas do Granito Serra da Providência (Scandollara et. al., 1999).

O objetivo deste trabalho é aplicar a metodologia geofísica à localização de mineralizações manganesíferas, na região de Castanheira - MT, baseada nos contrastes elétricos dos elementos em subsuperfície. A origem do manganês no local estudado não é muito conhecida, e é atribuída principalmente à soluções hidrotermais, dada a ocorrência do manganês ao redor de intrusões graníticas (Figura 1). O minério de manganês apresenta estrutura maciça e radial, sem presença de contaminantes, que corrobora com a origem ígnea do depósito (Figura 2).

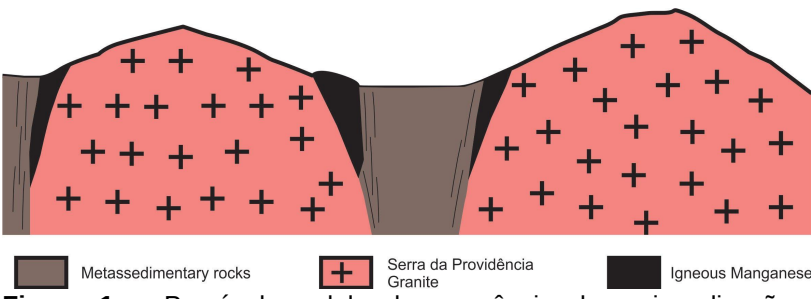

Figura 1 - Provável modelo de ocorrência das mineralizações manganesíferas na área de estudo (Castanheira - MT).

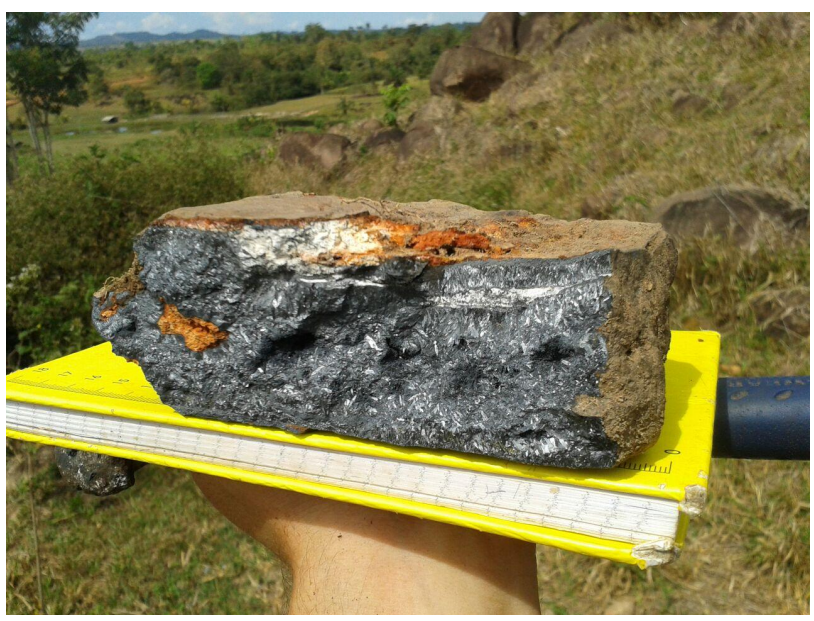

Figura 2 - Foto da amostra do minério de manganês da área de estudo, que evidencia a estrutura de crescimento dos cristais.

\section{Metodologia}

A escolha das localidades para a disposição das linhas de eletrorresistividade foi baseada em dados aerogeofísicos, nas regiões de anomalia de tório e potássio, já que a ocorrência do manganês está associada à corpos graníticos. Este cenário é ideal para a aplicação do método da eletrorresistividade, dado o alto contraste de propriedades elétricas: o granito, rocha ígnea de baixa porosidade, apresenta alta resistividade; o manganês, por conta da gênese hidrotermal associada à eventos ígneos, possui características elétricas condutivas.

$\mathrm{Na}$ aquisição de dados em campo usou-se a técnica de caminhamento elétrico, também conhecida como tomografia elétrica 2D quando realizada com equipamentos multieletródicos que possibilitam o registro de uma elevada densidade espacial de dados. A tomografia elétrica possibilita a verificação lateral e vertical da resistividade ao longo do meio, e é empregada na prospecção mineral para detectar corpos geológicos de condutividade anômala. No campo utilizou-se o 
arranjo eletródico dipolo-dipolo, com espaçamento entre os eletrodos de 5 metros e 10 metros (somente linha 5), com 19 níveis de investigação, o que possibilitou investigar até a profundidade de 36 metros. Nas aquisições de dados usou-se o resistivímetro mulltieletródico Syscal Pro (Figura 3), multicabos e eletrodos de aço. Durante os registros de dados usou-se uma tensão fixa de $400 \mathrm{~V}$ e ciclos de corrente de $250 \mathrm{~ms}$. $\mathrm{Na}$ área adquiriram-se dados ao longo de 5 perfis no sentido NW/SE.

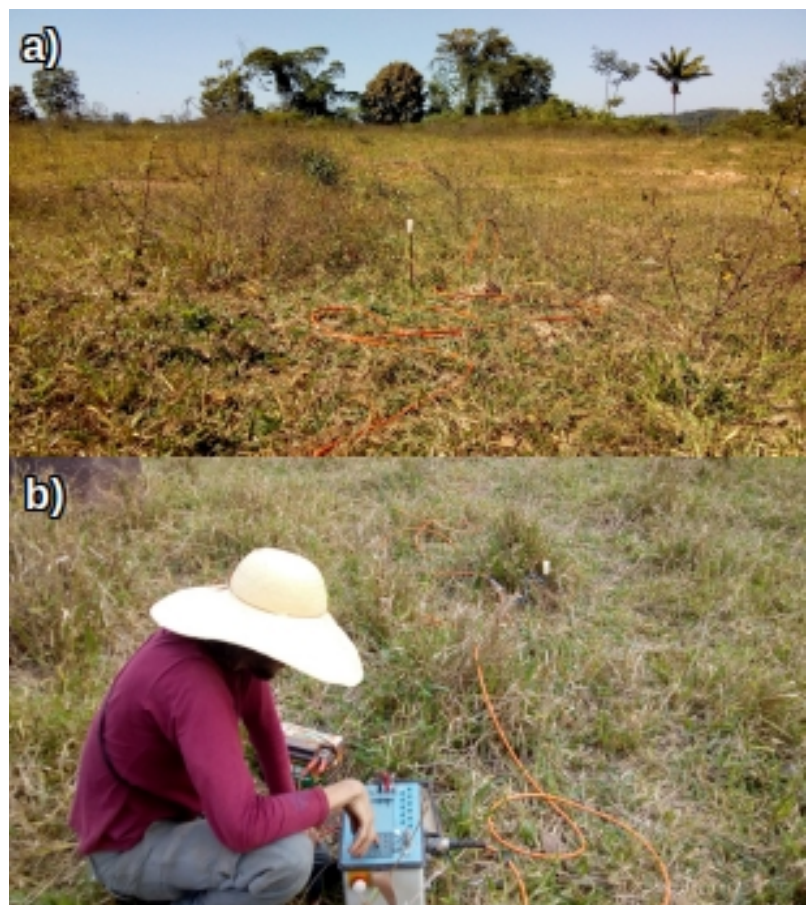

Figura 3 - Fotos da aquisição dos dados. a) Linha de aquisição. b) Resistivímetro Syscal Pro durante a aquisição.

Os valores da resistência de contato entre eletrodo e solo verificam-se em campo, e a partir destes são realizadas as medidas para a alta qualidade dos dados. Quanto maior os valores de resistência de contato, maior resistência o meio irá apresentar em propagar a corrente e maior o nível de ruído e interferência no fluxo da corrente injetada no solo (IRIS, 1993 apud Borges, 2007). Os valores obtidos geralmente estavam na faixa de 3 a $15 \mathrm{~K} \Omega$, com exceções de algumas regiões, onde a resistência chegava a valores de até $50 \mathrm{~K} \Omega$. O ideal é que estes valores sejam abaixo de $20 \mathrm{~K} \Omega$.

Os dados de resistividade elétrica aparente obtidos foram filtrados pelo software PROSYS II, modelados pelo RES2Dinv e dispostos para visualização no Oasis Montaj (Figura 4).

No software PROSYS II removeram-se os registros muito acima da média (spikes), retiraram-se dados com valores muito altos de resistência de contato (acima de $20 \mathrm{~K} \Omega$ ) e dos pontos onde não houve passagem de corrente (corrente nula).
O software RES2Dinv foi usado para a realização da modelagem inversa. O processo de inversão determina um modelo bidimensional de resistividade para o meio, em função da distribuição dos pontos de campo. O usuário pode alterar a espessura e tamanho dos blocos a fim de ajustar de forma mais correta os pontos ao modelo de blocos. De acordo com Lago (2009), "o método de otimização por mínimos quadrados, utilizado pelos programas de inversão, tenta reduzir a diferença entre os valores de resistividade aparente medidos e calculados ajustando a resistividade dos blocos, e esta diferença é dada pelo erro Root Mean Squared (RMS)". A proposta é encontrar o modelo com menor erro RMS, porém, este pode mostrar variações irreais que não contemplam de maneira correta a geologia em subsuperfície. Assim, o ideal é não somente um erro RMS baixo, como também um modelo em que a iteração anterior não tenha mudança significativa. Lago (2009) explicita que isso ocorre, geralmente, entre a terceira e quinta iterações.

Os perfis foram georreferenciados no software Oasis Montaj.

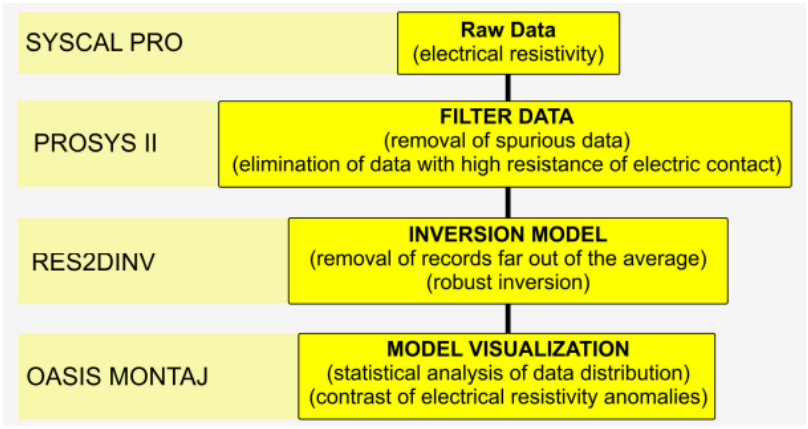

Figura 4 - Fluxograma de aquisição, modelagem e visualização dos dados de resistividade elétrica adquiridos neste trabalho.

\section{Resultados}

As seções obtidas são similares (Figuras 5, 6, 7, 8 e 9), com uma camada superficial de alta resistividade (interpretada como solo seco), seguida por uma camada condutiva e um embasamento com valores altos de resistividade elétrica (granito Serra da Providência, baixa porosidade). A região condutiva tem características de uma zona intemperizada saturada em água, porém, como a assinatura geofísica do minério manganês é de condutividade e os perfis coincidem com a presença do manganês em superfície, há possibilidade de a anomalia condutiva ter sido causada pela mineralização manganesífera.

A Figura 10 apresenta um corte em profundidade (15 metros) dos modelos inversos de resistividade obtidos. Nele, há uma correlação dos perfis e espacialização da distribuição de anomalias de baixa resistividade, relacionadas à possível mineralização manganesífera de gênese hidrotermal. 


\section{Matos, W. Borges, V. Pinto, C. Calachibete, M. Paula, I. Almeida}

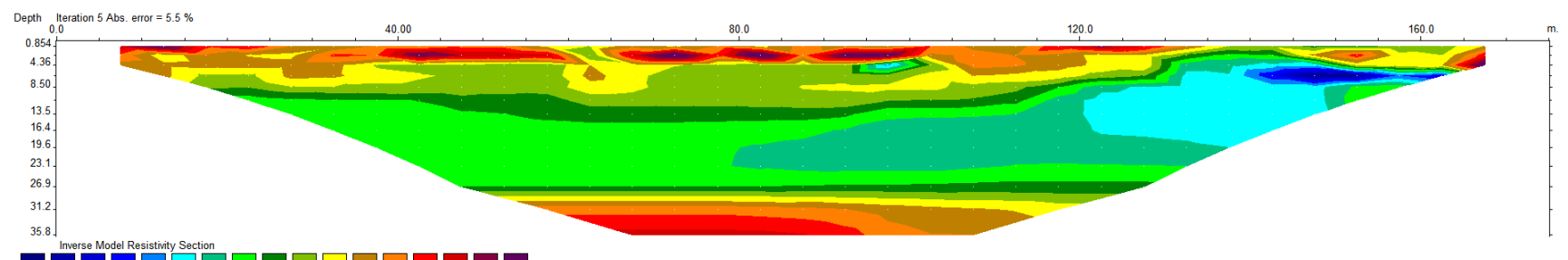

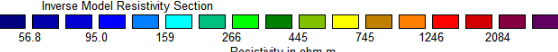

Figura 5 - Modelo inverso de resistividade da Linha 1. A região de baixa condutividade está possivelmente relacionada à mineralização manganesífera.

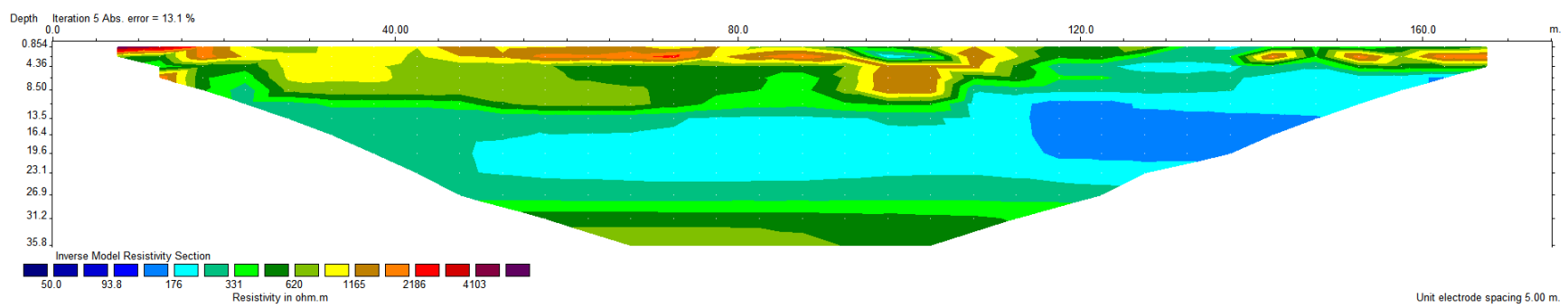

Figura 6 - Modelo inverso de resistividade da Linha 2. A região de baixa condutividade está possivelmente relacionada à mineralização manganesífera.

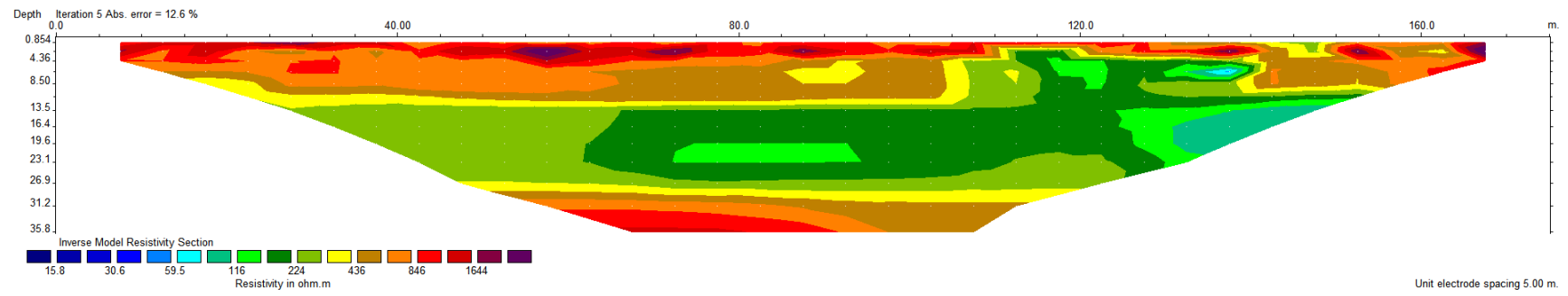

Figura 7 - Modelo inverso de resistividade da Linha 3. A região de baixa condutividade está possivelmente relacionada à mineralização manganesífera.

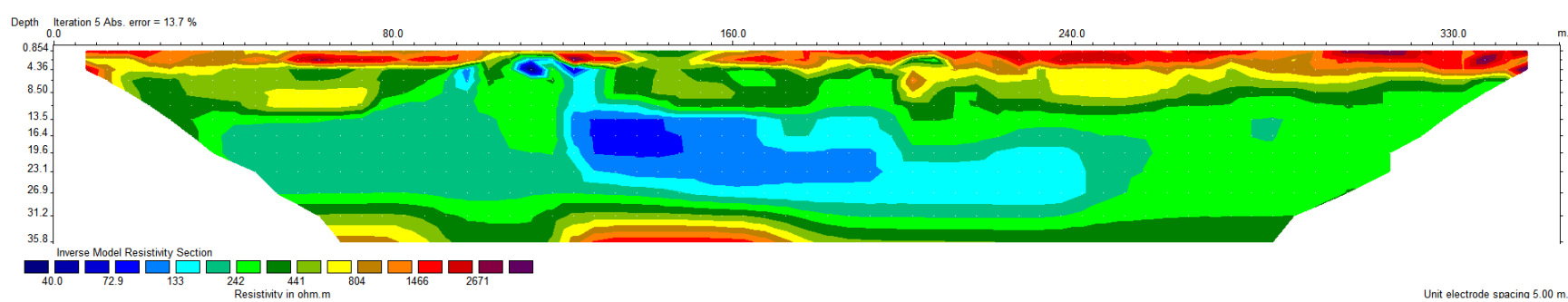

Figura 8 - Modelo inverso de resistividade da Linha 4. A região de baixa condutividade está possivelmente relacionada à mineralização manganesífera.

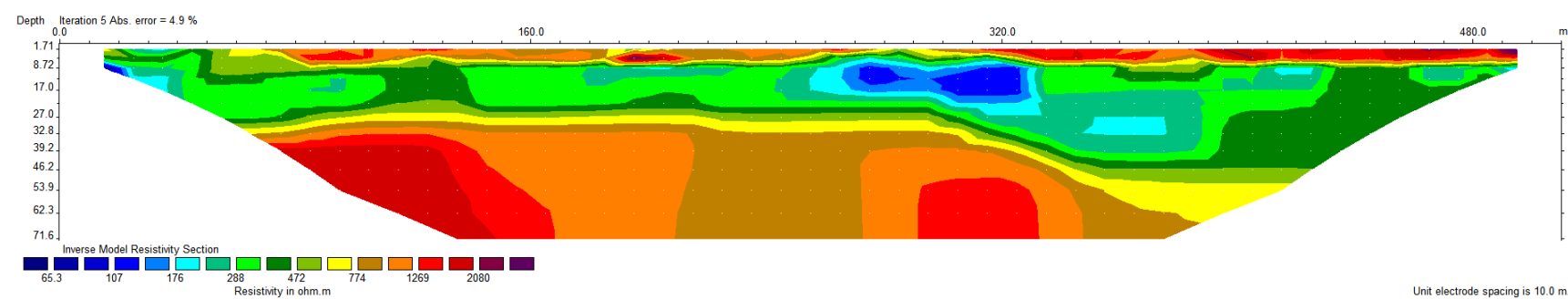

Figura 9 - Modelo inverso de resistividade da Linha 5. A região de baixa condutividade está possivelmente relacionada à mineralização manganesífera. 


\section{Conclusões}

$\mathrm{Na}$ área de estudo, foram observados alguns locais onde ocorreu atividade de extração superficial do manganês realizada por mineradores de pequeno porte. Como a mineralização do manganês ocorre em estruturas verticais, a localização dos perfis de eletrorresistividade situou-se próxima ou logo acima dos pontos onde houve extração do minério.

As aquisições 2D foram executadas com um sistema multieletródico. Nos perfis de resistividade elétrica obtidos após a rotina de inversão, identificaram-se estruturas horizontais e verticais a uma profundidade de até 36 metros. Os resultados da resistividade elétrica mostram que as mineralizações manganesíferas ocorrem como anomalias de baixa resistividade (abaixo de 200 $\Omega . m)$.

Os modelos obtidos mostram que as anomalias têm extensão de, aproximadamente, 40 metros e espessura de cerca de 20 metros. O embasamento granítico

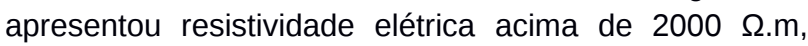
enquanto a zona intemperizada compreendeu valores a partir de $500 \Omega$.m (valores de resistividade maiores que o manganês).

\section{Referências}

LUIZ, J.G. Geofísica na Prospecção Mineral: Guia para Aplicação. $1^{a}$ ed. Rio de Janeiro, BRA: SBGf, 2013.

SCANDOLARA, J.E.; AMORIM, J.L.; RIZZOTO, G.J.; QUADROS, M.L.E.S.; BAHIA, R.B.C. Compartimentação Tectonoestratigráfica PréCambriana de Rondônia: Subsídios para os Modelos Evolutivos. Em: SBG, Simpósio de Geologia da Amazônia, 6, Manaus, Resumos Expandidos, 282-285. 1999.

LAGO, A.L. Investigação geofísica 2D e 3D com aplicação em meio ambiente: estudo sobre uma área de disposição de resíduos de óleo lubrificante no município de Ribeirão Preto - SP. 2009. Tese (Doutorado) - Instituto de Astronomia, Geofísica e Ciências Atmosféricas, Universidade de São Paulo, SP, 2009.

BORGES, W.R. Caracterização Geofísica de Alvos Rasos com Aplicações no Planejamento Urbano e Meio Ambiente: Estudo sobre o Sítio Controlado do IAG/USP. 2007. 256p. Tese (Doutorado) - Instituto de Astronomia, Geofísica e Ciências Atmosféricas, Universidade de São Paulo, SP, 2007.

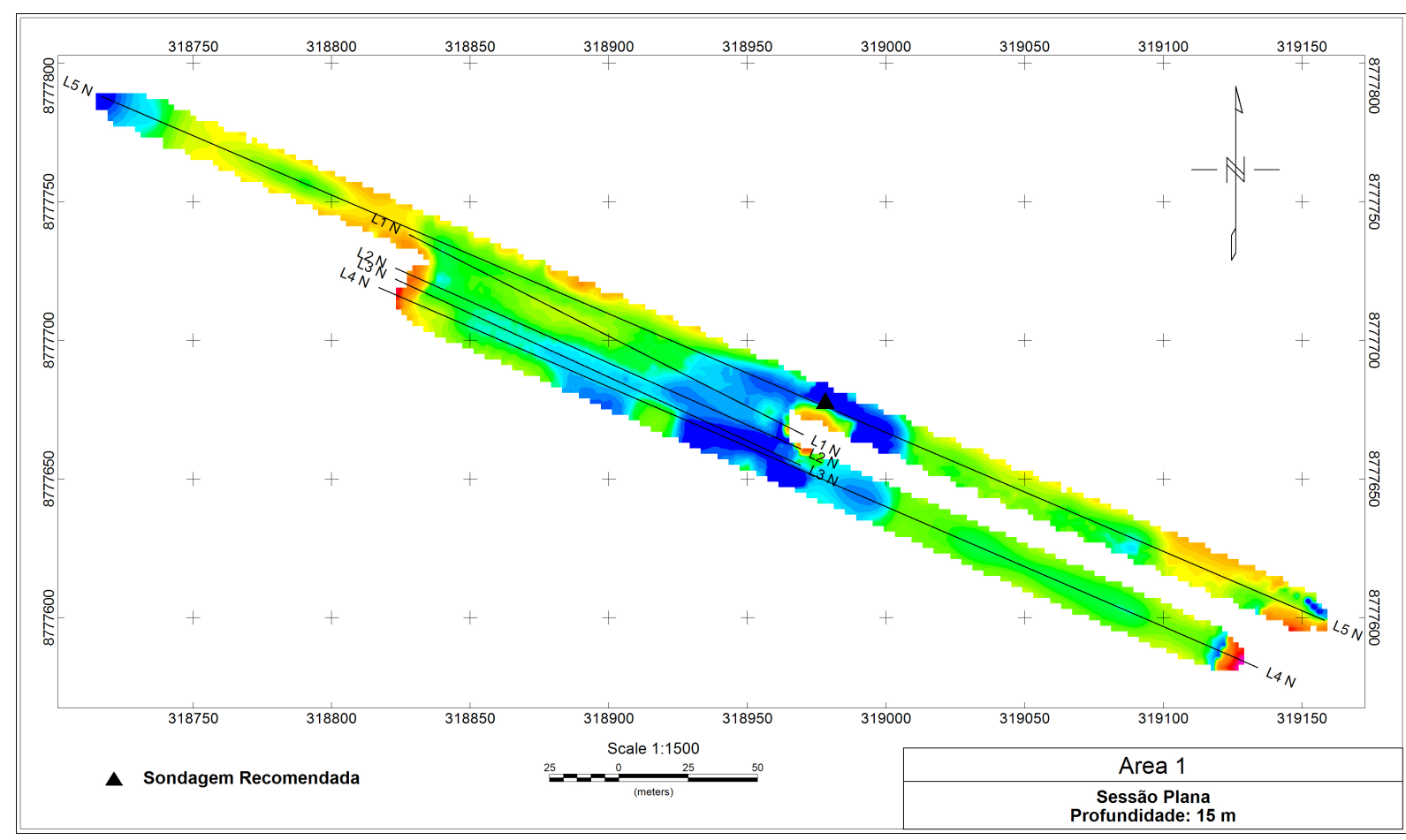

Figura 10 - Corte em profundidade (15 metros) dos modelos inversos de resistividade (Linhas 1 a 5) com anomalia de baixa resistividade possivelmente relacionada à mineralizações manganesíferas. 